\title{
Mídia eletrônica e um convite à colaboração em projetos artísticos e culturais
}

\section{RESUMO}

Este trabalho propõe-se a mostrar práticas que usam mídia eletrônica para auxiliar no processo de colaboração em projetos artísticos e culturais. Projetos que usam a internet, telefonia celular, GPS, redes wi-fi, dentre outros meios, conseguem mobilizar um grande número de pessoas a colaborarem, a produzirem e a terem um posicionamento ativo. Também é objetivo deste trabalho um convite à colaboração sendo que muitos destes projetos só funcionam se as pessoas participarem. Iniciativas existem muitas, o que falta é criar no público uma educação para a atividade. A mídia eletrônica possibilita e facilita criações artísticas e culturais, cabe aos educadores e produtores culturais desenvolver habilidades e motivação para tal.

\section{PALAVRAS-CHAVE \\ - mídia \\ - colaboração \\ - tecnologia}

\section{ABSTRACT}

This paper intends to show practices that use electronic media to enhance the process of collaboration in artistic and cultural projects. Projects that use the Internet, mobile phone, GPS, wi-fi networks, among other media, can mobilize a great number of people to collaborate, to produce, to have an active behavior. It is also the objective of this paper to make an invitation to collaboration, having in mind that many of these projects only work if people participate. There are many initiatives, however, there is a lack for creating in the public an education to the activity. The electronic media enable and facilitate artistic and cultural creations, and it is a duty of the educators and cultural producer to develop in people the ability and motivation for that.

\section{KEY WORDS}

- media

- collaboration

- technology

\section{Karla Schuch Brunet UFB}

C om o intuito de estudar como a mídia eletrônica é usada nos projetos colaborativos culturais e artísticos, primeiramente será feita uma abordagem sobre tecnologia e conceitos. Como trabalhos colaborativos não são novidade no campo da arte e da cultura, apresenta-se aqui alguns movimentos precursores aos projetos eletrônicos de hoje em dia.

Neste trabalho, optou-se por evitar o uso da terminologia "novas tecnologias" no título, pois muitos dos instrumentos tecnológicos considerados novos já existem por algumas décadas, como no cada da internet. Além do que, é subjetivo dizer o que é considerado novo ou não. "Novas tecnologias", portanto, é uma denominação temporária, o novo de hoje já não será mais no futuro. Logo, a denominação aqui usada para referir-se ao que muitos consideram "novas tecnologias" é "mídia eletrônica". Usando como base a categorização de novas tecnologias feita por Mark Tribe e Reena Jana (2006) no livro "Arte y nuevas tecnologías", este trabalho considera mídia eletrônica: a internet (tanto elementos de hardware como software, servidores, routers, base de dados, scripts...), câmeras digitais (câmeras de vigilância, webcams...), telefonia celular, computadores portáteis, GPS e redes sem fio.

\section{Tecnologia}

Muitos projetos artísticos e culturais usam a tecnologia para aprimorar sua habilidade de interação e conexão de pessoas. Antes da Internet, por exemplo, era impensado tais comunidades que ligavam pessoas em diversas partes do mundo sem levar dias, semanas e até meses. Hoje em dia, esta conexão é muito mais rápida, eficiente e barata.

A forma como vemos a tecnologia e, também, a forma com que vemos através dela, são alguns dos conceitos tratados por Paul Virilio. Quando fala sobre novas tecnologias, o autor (Virilio, 2000) usa o termo "small optics" e "big optics" para descrever a maneira com que as vemos. A "small optics" refere-se ao passado, enquanto que "big optics" é hoje em dia, onde já não existe mais a noção de horizonte, distância e espaço. Lev Manovich (2002, p.172) comenta esta diferenciação que Virilio faz dizendo "At least in principle, every point on earth in now instantly accessible from any other point on earth. As a consequence, Big Optics locks us in a claustrophobic world without any depth or horizon; the earth becomes our prison". ${ }^{1}$

Para melhorar, acelerar e facilitar a realização de algumas tarefas, a tecnologia digital é a ferramenta escolhida por muitos dos projetos colaborativos culturais e artísticos. Seria difícil de imaginar este tipo de 
projeto sem estas ferramentas. A tecnologia pode abrir os horizontes por possibilitar um amplo alcance e, ao mesmo tempo, pode restringir por ser precisa e específica.

\section{Fluxus e Mail art estavam baseados na transformação, na experimentação, no uso de tecnologia, na criação de uma comunidade global, na temporalidade.}

Tecnologia como transformação e não como informação é o conceito de Bruno Latour. Para o autor (Latour, 2002, p. 155) “There is only transformation. Information as something that will be carried through space and time, without deformation, is a complete myth. People who deal with technology will actually use the practical notion of transformation". ${ }^{2}$ De acordo com Latour uma imagem isolada não é informação, não tem significado. Imagens são momentos de transformação.

Esta transformação, vista de outro ângulo, é o que acontece em muitos dos projetos colaborativos. As pessoas incorporam um objeto como imagem ou música e o transformam. A assimilação das idéias são processadas e expelidas não como simples informação, mas como algo transformado, adicionado e mudado.

Uma teoria interessante sobre nova mídia e tecnologia é a analogia com o espelho retrovisor feita por Paul Levinson em seu livro "Digital Mcluhan". O autor (Levinson, 1999) afirma que em nova mídia, como a web, nós temos a tendência de usá-la como uma antiga mídia. Nós usamos internet como lendo um livro, escutando uma rádio ou conversando num café. Isto acontece porque ainda não estamos acostumados com a nova mídia então a usamos como uma que já conhecemos, de formas que já estamos confortáveis. É como se estivéssemos sempre olhando através de um espelho retrovisor ao invés de olhar para frente.

Levinson (1999) também argumenta sobre uma educação de novas tecnologias, sobre a possibilidade de aprender a mídia. Como uma educação online que fosse mais sobre aprender a estar online do que sobre qualquer tópico em particular.

É hora de aprender as novas tecnologias, assim como aprendemos a escrever e falar. Para que estas tecnologias funcionem a nosso favor, precisamos estar preparados para usá-las e a ser parte delas. A maior parte do tempo as pessoas estão usando as novas tecnologias como as antigas. Por exemplo, navegam pela internet como se estivessem lendo um jornal ou assistindo à televisão. Neste ponto é que entra a educação: em sendo educados para as possibilidades tecnológicas, as pessoas poderão mais rápida e eficientemente fazer uso delas. Concluindo, ser não somente receptores, entretanto, ser, ao mesmo tempo, produtores de informação.

\section{Alguns precursores}

Seria impossível dizer que os projetos colaborativos artísticos e culturais ocorrem somente pelas facilidades mídia eletrônica. Muitos projetos similares já eram realizados, por exemplo, antes da popularidade da Internet ou do telefone celular. A seguir estão alguns dos movimentos precursores aos projetos que analisamos para este estudo.

\section{Fluxus and mail art}

A importância do movimento Fluxus para este estudo está baseada na formação de redes e na participação. Organizado nos anos 60 por um de seus membros, George Maciumas, Fluxus era visto como uma "prática pluralística envolvendo grupos de artistas" (Higgins, 2002). Outros diriam que fluxus foi pensado como "meios de troca de informação e não como um estilo de movimento de arte" (Smith, 2005, p. 119). Maciumas era um imigrante lituano e colecionador de arte que organizava eventos, os festivais de performance fluxus, apresentando grupos de artistas fazendo trabalhos experimentais e publicando uma revista chamada "Fluxus".

Fluxos era um movimento internacional, particularmente forte nos Estados Unidos e Alemanha, mas com praticantes em vários países europeus e no Japão. Eles tinham uma grande variedade de práticas: música, performance, vídeo e arte conceitual. Sendo os "happening" suas práticas mais populares, estes eventos usavam a audiência como um participante ativo da obra.

Charlie Gere (2002), em "Digital Culture", vê Fluxus como um grande influenciador da arte digital de hoje em dia pois a interatividade e a comunicação eram sua principal característica. "It also presumed on the existence of noise, interference and distortion that would change messages in unpredictable ways. Fluxus also reflected a world linked by increasingly complex systems of communication and connection" ${ }^{3}$ (Gere, 2002, p. 85-86).

Estas redes, criadas por Fluxus, eram uma forma de conectar sua comunidade internacional. Além disso, eles o faziam como meios de comunicação tais como telefone, fax, satélite e correspondência postal.

Influenciados pelos colegas contemporâneos e por movimentos prévios como o dada e surrealismo, mail art surgiu como uma forma de arte aberta, colaborativa e geograficamente não delimitada. Suas exibições não tinham júri e toda arte recebida deveria ser exibida. 
Em meados dos anos 50, Ray Johnson começou mandando seus trabalhos de design gráfico para muitas pessoas do meio artístico. Ele criou uma lista postal para distribuição de trabalhos e, a partir desta, criou uma comunidade artística em rede que mais tarde se chamou New York Correspondance School. A palavra "correspondance" foi escrita com "a" ao invés de "e" como em "correpondence" (correspondência) para enfatizar a idéia de performance (dance) da obra (Held, 2005: 90). Sua "performance" era mandar um trabalho artístico por correio para alguém e pedir para esta pessoa reenviar a outro. A idéia era que estas duas pessoas pudessem assimilar o trabalho de formas diferente. E, portanto, criar uma comunidade de artistas mandando trabalhos um para outro através de uma terceira pessoa. Complementando, John Held (2005: 90) disse que "Mailings were affordable, reached everywhere, and could be used for either promotion or anonymity. They could convey mystery, blending the separation of art and life." 4

Em 1971, um manifesto chamado NET foi publicado convocando artistas a participaram e serem curadores de uma exposição não-comercial e não-hierárquica. Ele pronunciaram, dentre vários outras declarações, que "NET pode ser arbitrariamente desenvolvida e copiada" (Perkins, 2005, p. 395). Poderia, este manifesto, ser considerado como uma forma antecipada de propagação de licenças de copyleft em arte.

Concluindo, Fluxus e Mail art estavam baseados na transformação, na experimentação, no uso de tecnologia, na criação de uma comunidade global, na temporalidade... Todas estas características podem ser aplicadas aos projetos colaborativos artístico-culturais na Internet, que, de alguma forma, foram incentivados por estes movimentos.

\section{Guerrilla TV}

Guerrilla TV começou no final dos anos 60 como um movimento para democratizar a televisão, tinha como objetivo dar acesso às pessoas a produzirem televisão. Isto aconteceu, principalmente nos Estados Unidos, quando a câmera de vídeo diminuiu de tamanho e ficou mais barata, quando algumas cidades começaram a ser interligadas por televisão a cabo, e quando os governos distribuíram licenças para televisões comunitárias a cabo. Era um ponto de partida para uma mídia aberta e acessível.

Grupos estavam usando vídeo para criar documentários, trabalhos artísticos, ativismo e programas comunitários, muitos destes estavam baseados numa forma de trabalho colaborativa. Eles iam a escolas, centros cívicos, reuniões sociais para produzir vídeos com uma argumentação critica e social. Alguns nomes importantes do Guerrilla vídeo foram: Ant Farm, video magazine Radical Software, Videofreex, People's Video Theater, Global Village, Raindance Corporation e Paper Tiger Television Collective.
Mesmo que seus vídeos tivessem uma base política, comunitária e trabalhavam com direitos humanos, infelizmente, eles ficaram fora da televisão convencional e, também, da maioria da população. O público era na maioria segmentado, estudantes universitários e legiões de contra-cultura (Trend, 1995).

No final dos anos 90, Laura Baigori (1998) escreveu um texto intitulado "The future is not what is used to be. From Guerrilla Television to Resistance on the Web", no qual ela compara a Guerrilla TV com os movimentos de ativismo na web. Segundo a autora, o vídeo era usado como uma arma para lugar contra o sistema. Ativistas e artistas queriam democratizar a tecnologia e apresentá-la ao público. Somente hoje em dia, em plataformas como YouTube e Vimeo, é que se começa a ver um pouco desta democratização, do público não-profissional produzindo vídeo e de um grande número de pessoas assistindo a estes vídeos.

Em um artigo chamado "The Revenge of Lowtech: Autolabs, Telecentros and Tactical Media in São Paulo", Ricardo Rosas (2004) aponta para o "low tech" como a melhor solução para países com uma grande discrepância econômica como o Brasil. Um país onde somente algumas poucas empresas, que dominam a mídia de massas, controlam a opinião pública. Deste modo, resta aos ativistas e produtores culturais, possibilitados pela mídia "low tech", buscar por um fresta neste sistema para pronunciar seus pontos de vista.

\section{A função de Yellow Arrow é apontar coisas e/ou lugares que chamam a atenção, lugares que têm algum significado.}

Uma prática paralela à Guerrilla Tv eram as rádios comunitárias. Existiam milhares de rádios por toda parte usando freqüências FM e AM para difundir programas feitos pela e para a comunidade. Estas eram rádios que criaram um espaço aberto para a comunidade falar. Além disso, rádios comunitárias eram normalmente sem fins lucrativos e não-comercial, algumas eram ilegais, as chamadas rádios piratas. Hoje em dia, muitas destas rádios seguem ativas e continuam a difundir, agora também na rede, as chamadas "net rádio".

\section{Projetos colaborativos artísticos e culturais}

Mídia eletrônica, como a internet e o celular, estão sendo cada vez mais utilizadas para criar projetos colaborativos artísticos e culturais. Estes projetos fazem parte de uma cultura livre onde todos podem participar, produzir, ser parte ativa da sociedade. 
Dentre uma grande gama de projetos estudados e analisados ${ }^{5}$, cita-se aqui alguns exemplos de projetos abertos à colaboração do público Yellow arrow, Wikipedia, Vimeo e YouTube, Flickr e Fotki, Mirror Project, Scene from my life, Opserver, Delicious, Recombo, Mundo al revés, Impossíveis, Freesound, Esc for scape... Abaixo está uma pequena descrição de alguns deste projetos, formas de colaboração e mídia utilizada.

\section{Global Yellow Arrow (http://yellowarrow.net/)}

Global Yellow Arrow é um projeto de intervenção urbana onde os participante são convidados a colar um adesivo de uma flecha amarela (Yellow Arrow ) em lugares que lhes interessam. Cada flecha tem um código de números e letras, como por exemplo "yw

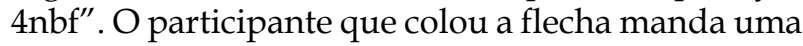
mensagem ao website referente ao código. Quando outra pessoa vê o adesivo, ela pode enviar uma mensagem (SMS) do celular com o código da flecha. Automaticamente, ela recebe de volta uma mensagem SMS com o texto guardada no site referente àquele código. Muitos usuários, também, fazem fotos do local onde colaram a flecha e enviam como documentação para o site. Como exemplo, o texto referente ao código "yw 4nbf" citado anteriormente é: "This library does not make it into the tourist guidebooks. But go in and look. Its a relic of SFs 1930s civic optimism. Very cool "O usuário, Skat, que colou a flecha perto da biblioteca pública de San Francisco tenta, com isto, chamar atenção aos murais da cidade que referências artísticas marcantes na cultura local. ${ }^{6}$

O projeto, muitas vezes, feito de forma intensiva em alguma cidade, é aberto à participação do público e utiliza a seguinte mídia: internet, telefonia celular, câmara digital. A função de Yellow Arrow é apontar coisas e/ou lugares que chamam a atenção, lugares que têm algum significado. Desta forma as pessoas são encorajadas a prestarem atenção em coisas que normalmente não notariam.

\section{Wikipedia (http://www.wikipedia.org/)}

Wikipedia é uma enciclopédia online onde qualquer pessoa pode adicionar e editar o conteúdo. Uma das características mais impressionantes é a quantidade de artigos, tem um artigo para quase tudo que você quiser saber ${ }^{7}$. Dez anos atrás, ninguém imaginaria que uma enciclopédia colaborativa feita por voluntários teria um número muito maior de artigos que suas concorrentes comerciais criadas por grandes corporações como a Encarta e a Britânica ${ }^{8}$.

Como a Wikipedia é aberta a colaboração de todos, para manter um nível de nitidez nos seus artigos, alguns destes colaboradores podem tornar-se administradores. Os administradores são usuários comuns que eleitos pela comunidade zelam pela qualidade dos artigos. Neste caso a internet é o meio de divulgação do conteúdo, de captação dos voluntários e de edição do material.

\section{Flickr (http://flickr.com/) e Fotki (http:// www.fotki.com/)}

Flickr e Fotki são sites que possibilitam uma livre publicação, distribuição, compartilhamento e arquivo de fotografias na internet. Em espaços como este, usuários podem facilmente publicar suas fotos e fazer possível com que outros as vejam. Com a facilidade de fazer fotos com uma câmera digital, cada dia são produzidas milhões de fotos, por isto é importante projetos como estes que facilitam através de etiquetas, álbuns, links, o armazenamento deste material, caso contrário grande parte deste conteúdo seria perdida. Nestes sites são encontradas documentações fotográficas de muitos do importantes eventos da atualidade. São uma nova forma de informar visualmente, são fotografias, na maior parte, amadora mostrando o dia-a-dia.

\section{YouTube (http://www.youtube.com/) e Vimeo (http:// www.vimeo.com/)}

YouTube e Vimeo são projetos similares a Flickr e Fotki mas com vídeo, são sites que proporcionam um espaço para a divulgação e armazenamento de vídeos na internet. Com a facilidade e rapidez de postagem da internet, YouTube tornou-se febre. Quase todo dia recebemos email com link para vídeos, a eficiência e fácil usabilidade do site são responsáveis pela sua popularidade.

\section{A Wikipedia em inglês ou em alemão possui uma qualidade e quantidade muito superior à em português, para checar isto basta analisar artigos sobre um mesmo verbete nos três idiomas.}

No site, a variedade de temas é grande, de vídeos de amigos a artísticos ou como, por exemplo, vídeos feitos com celulares que documentam momentos importantes da nossa história. Canais como estes, abertos para a difusão de vídeos são exemplos práticos de que qualquer um pode produzir e de que muitos vão ver esta produção.

\section{Re:combo (http://www.recombo.art.br/)}

Re:combo é uma criação coletiva de música na rede. Começo em Recife e hoje em dia tem participantes em diversas partes do Brasil. Ele produzem música, colocam arquivos de MP3 na Internet para outros baixarem e, de alguma forma, serem motivados a recons- 
truir, remixar para depois colocar os resultados novamente na web. Re:combo está baseado em copyleft e trabalho coletivo. Não tem um autor mas sim vários autores anônimos, ou não, que criam e desfrutam da música.

O grupo também produz algumas performances onde fazem chamadas para música, sons, ruído, imagens... Estes acontecimentos ocorrem ao vivo em diversas partes do Brasil, nesta fase é que se mostra o novo material por eles produzidos.

\section{Del.icio.us (http://del.icio.us/)}

Del.icio.us é uma plataforma para guardar e compartilhar seus websites favoritos. Usando-se da folksnomia ${ }^{9}$, o site possui uma categorização por palavraschaves, não-hierárquica e desta forma proporciona que através das "tags" (etiquetas) se possa descobrir novos sites. É uma forma fácil e eficiente de organizar os sites de interesse e, também, colocá-los disponível a outros. Se você encontrou um website muito interessante na internet, por que não compartilhá-lo com outras pessoas?

\section{ESC for escape (http://www.desvirtual.com/escape/ portugues/)}

Um trabalho que envolve mídias como a internet, sms, mms, painéis eletrônicos, DVD. É um trabalho que convida à colaboração, onde as pessoas são chamadas para enviarem mensagens de erro que recebem frequentemente na rotina rodeada por tecnologia.

O público participou enviando imagens e textos das mensagens de erro. Com a facilidade dos celulares modernos terem câmera acoplada, o erro podia instantaneamente ser documentado e enviado. O material recebido era apresentado em painéis eletrônicos na Avenida Paulista e, também, fez parte de um DVD.

\section{Concluindo: noção de "commons" e convite a colaborar}

Para poder construir uma cultura livre e uma sociedade democrática é importante uma participação ativa de seus membros. É claro que quando se fala em mídia eletrônica, em um país como Brasil, ainda significa uma minoria da população. Contudo, esta minoria sim que poderia e deveria ser ativa.

Ao ler textos como "Os enciclopedistas franceses rolam nos túmulos", muitas perguntas emergem. A autora (Ribeiro, 2007), ao criticar projetos como a Wikipedia, diz: "Todas as vezes que caí na Wikipedia, achei os textos mal-escritos, ruins e confusos." A primeira e principal pergunta é: "Por que não arrumar os textos mal-escritos e confusos?" Criticar é fácil, mas editar um texto na Wikipedia para uma professora universitária é, também, muito fácil.

Projetos como Wikipedia são feitos para todos e por todos, mas ainda não temos a cultura de produzir, de fazer algo por todos. Talvez por vivermos em uma país onde não se conhece a noção de "commons".

\section{Um ponto relevante deste artigo está em chamar 0 público em geral, estudantes, artistas, acadêmicos, produtores culturais à colaboração.}

Este seria mais um ponto a ser trabalhado com estudantes: criar a noção de que existem coisas comuns à comunidade e que devemos zelar por elas.

A denominação "commons", difícil de ser traduzida para o português, surgiu na Inglaterra para referirse a coisas "common goods" que eram comuns à uma comunidade. Era considerado "common" a terra na qual os campesinos de um vilarejo usavam para pastar seu rebanho. Hoje em dia, este conceito abrange um número maior de coisas, como, por exemplo, em ecologia onde a água dos oceanos e o ar é comum a todos.

Explicando melhor, Yochai Benkler (2003), em The Political Economy of Commons, define "commons" dizendo:

Commons are a particular type of institutional arrangement for governing the use and disposition of resources. Their salient characteristic, which defines them in contradistinction to property, is that no single person has exclusive control over the use and disposition of any particular resource. Instead, resources governed by commons may be used or disposed of by anyone among some (more or less well defined) number of persons, under rules that may range from 'anything goes' to quite crisply articulated formal rules that are effectively enforced. ${ }^{10}$

Em 1968, Garrett Hardin (1968) publicou um texto intitulado "Tradedy of the commons" onde examinava o uso irresponsável e livre dos bens comuns e a escassez que isto pode gerar. Porém, quando se trata de mídia eletrônica, Lawrence Lessig (2001) mostrou que esta preocupação já não mais é relevante. Segundo o autor, "commons" podem ser divididos em rivais e não rivais. Rivais são quando o uso de um pode gerar escassez para outro e não-rivais são quando o uso não gera escassez, que é, por exemplo, o caso do conhecimento. Se uma pessoa compartilha o conhecimento com outras, ela não vai perdê-lo por ter compartilho. Diferente de quando se compartilha uma laranja, um fica com menos para que outro também a tenha.

Tratando-se de mídia eletrônica, se alguém, por exemplo, compartilha arquivos de mp3, isto não vai 
gerar escassez de arquivos de mp3, pelo contrário, vai gerar várias cópias idênticas do mesmo. Esta noção de "commons" não-rivais é estimulada em muitos projetos artísticos e culturais em mídia eletrônica. Voltando ao exemplo da Wikipedia, se um usuário escreve verbetes de seu conhecimento na enciclopédia online, ele não vai perder este conhecimento, mas sim, muitos outros poderão usufruir do mesmo.

\section{As ferramentas estão disponíveis, são fáceis, é somente usá-las de forma inteligente e criativa.}

Pode-se perceber que em países onde a noção de "commons" existe, este tipo de trabalho é bem mais valorizado. Tomando como modelo, a Wikipedia em inglês ou em alemão possuem uma qualidade e quantidade muito superior à em português, para checar isto basta analisar artigos sobre um mesmo verbete nos três idiomas. Nestas comunidades, a wikipedia foi incorporada por muitas escolas e universidades. Na Alemanha, eles criaram um concurso de artigos e divulgaram na mídia. Além de receberem muita colaboração, houve uma preocupação com a qualidade dos textos.

Para estimular a colaboração de estudantes e educadores, Wikipedia tem uma seção chamada "Wikipedia: school and university projects". Esta serve para promover a elaboração dos artigos, onde professores passam tarefas aos alunos para produzir conteúdo para Wikipedia. Todo ano, milhares de trabalhos dos alunos vão para o lixo ou ficam guardados em gavetas, por que não publicar este material para a comunidade?

Neste artigo uso o exemplo da Wikipedia por ter sido instigada quando li crítica citada anteriormente, mas este convite à colaboração se estende a todo e qualquer projeto cultural e artístico. Navegando pela internet pode-se encontrar uma grande diversidade de trabalhos, assuntos e pontos de vista com diferentes níveis de envolvimento, qualidade e popularidade. Basta escolher um que se adapte às suas necessidades e capacidades.

Um ponto relevante deste artigo está em chamar o público em geral, estudantes, artistas, acadêmicos, produtores culturais à colaboração. É um convite não somente à colaboração de projetos já existentes, mas, também, um convite para a criação de novos projetos. Não devemos ficar sentados vendo a história passar, vamos fazer um pouco desta história. As ferramentas estão disponíveis, são fáceis, é somente usá-las de forma inteligente e criativa.
1. Minha tradução: "Ao menos em princípio, todo ponto na terra é, agora, instantaneamente acessível de qualquer outro ponto na terra. Como conseqüência, Big Optics nos tranca em um mundo claustrofóbico sem nenhuma profundidade ou horizonte; a terra torna-se nossa prisão".

2. Minha tradução: "Há somente transformação. Informação como algo que vai ser carregado através do espaço e tempo, sem deformação, é um completo mito. As pessoas que tratam com tecnologia realmente usarão as noções práticas de transformação".

3. Minha tradução: “Também supunha a existência de ruído, interferência e distorção que mudariam a mensagem de maneiras imprevisíveis. Fluxus também refletia um mundo ligado por um crescente e complexo sistema de comunicação e conexão."

4. Minha tradução: "O correio era possível de se pagar, alcançável em todo lugar, e poderia ser usado tanto para promoção quanto para anonimato. Eles podiam transmitir idéia de mistério, mesclando a separação entre a arte e a vida."

5. Aqui faço referência ao estudo realizado para a tese de doutorado, onde cataloguei 100 projetos, escolhidos de uma seleção de 400 . Hoje em dia, sigo realizando esta pesquisa com uma bolsa de pós-doutorado.

6. Veja a foto no website http://yellowarrow.net. Basta buscar pelo código da flecha. Acessado em junho 2007.

7. Aqui faço referência à Wikipedia em inglês que tem mais de 1.764.077 de artigos.

8. A wikipedia possui 3, 1milhões de artigos, enquanto que a Britannica possui 120 mil (32 volumes em papel) e a Encarta 45 mil. Acessado em junho de 2007 http:/ / pt.wikipedia.org/wiki/

9. Folksonomia segundo wikipedia: A folksnomia é uma maneira de indexar informações. Esta expressão foi cunhada por Thomas Vander Wal. É uma analogia à taxonomia, mas inclui o prefixo folks, palavra da língua inglesa que significa pessoas. http://pt.wikipedia.org/wiki/Folksonomia

10. "Commons" são um tipo de organização institucional para governar o uso e disposição dos recursos. Sua característica saliente, que os define em contraposição com propriedades, é que nenhuma pessoa sozinha tem o controle exclusivo sobre o 
uso e disposição de qualquer recurso específico. Ao invés disto, recursos governados por "commons" podem ser usados ou dispostos por qualquer um (mais ou menos bem definidos) dentre as pessoas, sob regras que podem varias de 'tudo entra' a regras formais duramente articuladas que são efetivamente impostas.

\section{REFERÊNCIAS}

BAIGORRI, Laura. El futuro ya no es lo que era. De la Guerrilla Television a la Resistencia en la red. Aleph-arts. Acessado November 2005. Disponível em http:/ / aleph-arts.org/pens/ baigorri.html 1998.

BENKLER, Yochai. The Political Economy of Commons. Upgrade. Acessado 2007. Disponível em http:/ / www.benkler.org/ Upgrade-Novatica\%20Commons.pdf 2003.

GERE, Charlie. Digital culture. London: Reaktion Books. 2002.

HARDIN, Garrett. The Tragedy of the Commons. Science. Acessado 2007. Disponível em http:/ /www.garretthardinsociety.org/articles/ art_tragedy_of_the_commons.html 1968.

HELD, John. The Mail Art Exhibition: Personal Worlds to Cultural Strategies. In: Chandler, Annmarie e Norie Neumark (Ed.). At a distance: precursors to art and activism on the Internet. Cambridge, Mass.: MIT Press, 2005.

HIGGINS, Hannah. Fluxus experience. Berkeley: University of California Press. 2002.

LATOUR, Bruno. There is no information, only transformation. An Interview with Bruno Latour. In: Lovink, Geert (Ed.). Uncanny networks: dialogues with the virtual intelligentsia. Cambridge, Mass.: MIT Press, 2002.

LESSIG, Lawrence. The future of ideas: the fate of the commons in a connected world. New York: Random House. 2001.

LEVINSON, Paul. Digital McLuhan: a guide to the information millennium. London; New York: Routledge. 1999.

MANOVICH, Lev. The language of new media. Cambridge, Mass.: MIT Press. 2002.

PERKINS, Stephen. Assembling Magazines and Alternative Artists' Network. In: Chandler,
Annmarie e Norie Neumark (Ed.). At a distance: precursors to art and activism on the Internet. Cambridge, Mass.: MIT Press, 2005.

RIBEIRO, Ana Elisa. Os enciclopedistas franceses rolam nos túmulos. Digestivo Cultural. Acessado. Disponível em http:// www.digestivocultural.com/colunistas/ coluna.asp?codigo=2251 2007 .

ROSAS, Ricardo. The Revenge of Lowtech: Autolabs, Telecentros and Tactical Media in São Paulo. In: Sarai, Centre for the Study of Developing Societies. (Ed.). Sarai Reader 04: Crisis, media. Delhi: Sarai Programme, CSDS, 2004.

SMITH, Owen F. Fluxus Praxis: An Exploration of Connections, Creativity, and Community. In: Chandler, Annmarie e Norie Neumark (Ed.). At a distance: precursors to art and activism on the Internet. Cambridge, Mass.: MIT Press, 2005.

TREND, David. The crisis of meaning in culture and education. Minneapolis: University of Minnesota Press. 1995.

TRIBE,Mark; JANA, Reena. Arte y nuevas tecnologías. Köln, Germany: Taschen. 2006.

VIRILIO, Paul. La grande optique. In: Weibel, Peter (Ed.). Zur Rechtfertigung der hypothetischen Natur der Kunst und der Nicht-Identität in der Objektwelt. Köln: Tanja Grunert, 2000. 